\title{
PATTERNS FOR DESIGNING ADAPTIVE/ADAPTABLE EDUCATIONAL HYPERMEDIA
}

\author{
F. Garzotto ${ }^{1}$, S. Retalis ${ }^{2}$ \\ 1) HOC - Hypermedia Open Center, \\ Department of Electronics and Information \\ Politecnico di Milano \\ Via Ponzio 34/5 - 20133 Milano \\ garzotto@elet.polimi.it, cantoni@elet.polimi.it
}

\author{
A. Papasalouros ${ }^{2} \quad$ K. Siassiakos ${ }^{2}$ \\ 2) University of Piraeus, Department of Technology \\ Education and Digital Systems \\ 80 Karaoli \& Dimitriou 18534 Piraeus \\ retal@unipi.gr, andpapas@softlab.ntua.gr, \\ siassiakos_k@ypan.gr
}

\begin{abstract}
A number of studies in traditional class based education show that students whose learning styles match with the instructional approach "tend to retain information longer, apply it more effectively, and have more effective post course attitudes towards the subject than do their counterparts who experience learning/teaching mismatch. Thus, the goals of a "good instructor" should be both to adapt, at some degree and at least part of the time, his or her instructional approach according to students' learning preferences, and to help students build their skill in their preferred and less preferred learning modes. Taking for granted that in a "student-centered" hypermedia learning environment, learning preferences and design of hypermedia learning applications should be also related, this paper aims to define the structure of the hypermedia design patterns that provide solutions to the problem of how to best support learning preferences via educational hypermedia applications and more specifically via adaptive/adaptable educational hypermedia applications.
\end{abstract}

\section{Key Words}

Adaptive hypermedia, design patterns, design model

\section{Motivations}

In an educational experience, different instructors adopt different instructional modes that correspond to their preferred "teaching style". Some focus on principles and others on applications; some present the material in a logical progression of small incremental steps, others proceed from the big picture to the details; some lecture and provide information using mainly spoken or written words, others like to present visual material, demos and experiments; some expect that students simply listen and watch, others provide frequent opportunities for discussing, questioning, and arguing.

On the other side, different students are characterized by different "learning styles, i.e., preferences or predispositions to behave in a particular way when engaged in a learning process. Different students preferably focus on different types of information, tend to operate on the perceived information in different ways, and achieve understanding at different rates.
A number of studies in traditional class based education $[1,2,3,4,5,6]$ show that students whose learning styles match with the instructional approach "tend to retain information longer, apply it more effectively, and have more effective post course attitudes towards the subject than do their counterparts who experience learning/teaching mismatch" [7]. On the other end, functioning effectively in any professional environment requires a lot of mental flexibility and the ability of working well in multiple learning modes. As a consequence, the goals of a "good instructor" should be both to adapt, at some degree and at least part of the time, his or her instructional approach according to students' learning preferences, and to help students build their skill in their preferred and less preferred learning modes.

In e-learning, where the human instructor is replaced, totally or partially, by a computer application, different instructional approaches correspond to different application properties, e.g., different types of content, different organization structures for the educational material, different interactive activities in which students are engaged, different kinds of tutoring and scaffolding in other words, different design solutions. Paraphrasing the claims in the above paragraph, we can say that a "student centered" e-learning application should aim at reducing the mismatch between the users' learning styles and the design solutions adopted by the application, but also, at some point during the e-learning experience, expose students to different instructional approaches.

We have investigated this issue in a specific category of e-learning systems, educational hypermedia, and, in particular, adaptive or adaptable educational hypermedia, such as ELM-ART, Interbook, AHA2, and many others [8]. With the term "educational hypermedia", we mean a multimedia interactive system which is mainly navigation-based and is built for educational purposes. An adaptive or adaptable educational hypermedia enriches the application functionality by maintaining a "representation of the user" (or "user model") and providing customization mechanisms to modify application features in response to user model updates. For adaptive hypermedia, user model updates are 
automatically generated by the system (by monitoring and interpreting the user's interactions); for adaptable hypermedia, user model updates are under the user control.

Our research attempts to identify examples of "good matches" between learning styles ${ }^{1}$ and application design solutions. These examples can be used as design guidelines both for educational hypermedia and for adaptive or adaptable educational hypermedia. Educational hypermedia designers can use them to build educational hypermedia that match a specific learning style. For adaptive or adaptable educational hypermedia, designers can use these guidelines to design high level customization mechanisms that provide different customized versions of the same application either to match a specific learning style or to expose learners to different instructional methods.

We model these guidelines in terms of design patterns. According to the classical definition of architect Alexander, the pioneer of design patterns (who applied them to architecture and urbanistics), “... a design pattern describes a problem which occurs over and over again in our environment, and then describes the core of the solution to that problem, in such a way that you can use this solution a million times over, without ever doing it the same way twice”.[9] In its simplest form, a design pattern is a recurrent problem associated to a design solution within a specific context. It provides a structure for integrating the analysis and solution of a problem, in a way that is sensitive to context and is informed by theory and evidence.

In our approach, the problem component of a design pattern is described by an instructional goal (e.g., a learning preference that the designer, or the application, needs to address); the solution component describes the desired design properties that the application should have, concerning its types of content, its organization structures, and interaction or navigation capabilities.

By its very nature, any design pattern is intrinsically heuristic, being founded on design practice. In our patterns, we try to capture the experience achieved in traditional educational frameworks and reported in the literature of pedagogy, cognitive science, and instructional design. These disciplines provide us both models for describing learning styles and instructional approaches that work well (at least in some authors' opinion) for some specific learning preferences. Our patterns attempt to translate "traditional" instructional design solutions in terms of hypermedia design properties and adaptive/adaptable behaviors.

\footnotetext{
${ }^{1}$ or learning “modes”, or learning "preferences“ - we consider these terms as synonymous, at least for the moment.
}

The rest of the paper is structured as it follows. Section 2 discusses the model we have adopted for representing learning styles. This section also introduces the design dimensions along which we can describe hypermedia application properties. In section 3 we present some examples of design patterns for traditional educational hypermedia, while section 4 discusses high level patterns for adaptive and adaptable hypermedia. In section 5 we draw the conclusions.

\section{Modeling Learning styles and Hypermedia Design}

"Learning style" is a broad concept which has many different meanings. In general terms, a learning style can be defined as a composite of characteristic cognitive, affective, and physiological factors that serve as relatively stable indicators of how a learner perceives, interacts with, and responds to a learning environment. Pedagogy and cognitive sciences provide a wide variety of learning styles models $[10,4,11,12]$ that often differ more in name than nature. In the following, we introduce the Felder/Silverman learning style model [4], one of the most used in engineering education - the field we are more familiar with. Still, our approach is largely independent from the chosen model, and the patterns we present refer to attributes that (although with different names) occur in most learning style models.

According to the Felder/Silverman model, a student learning style can be defined by a set of attributes, each one related to a different learning “dimension", as reported in Table 1.

According to most hypermedia design models [13, 14, 15, $16]$, the key features of a hypermedia application can be described in terms of four main design dimensions:

- the content (in the education domain, the educational material that the learner can explore in the application);

- the navigation and interaction capabilities by which (s)he can explore the content and interact with it;

- the activities in which the user can be engage and by which (s)he can modify the content and navigation structures (e.g., by marking some interesting material, by collecting material in personal "lessons") or the user representation (e.g., by answering some questions or tests);

- the lay-out, i.e., the concrete presentation on the screen of all the previous features.

Following the presentation philosophy adopted for describing learning styles, we describe design dimensions in terms of designer's questions and we provide some examples of their possible answers, or "design attributes", as reported in Table 2. Like a learning style is modeled as a combination of learning attributes, the design properties 
of a hypermedia application can be described as a

dimensions. combination of design attributes along the different

Table 1

Learning Styles Indicators (Felder/Silverman model)

\begin{tabular}{|c|c|c|c|}
\hline $\begin{array}{l}\text { Learning style } \\
\text { dimension: } \\
\text { Question } \\
\text { about... }\end{array}$ & & $\begin{array}{l}\text { Learning } \\
\text { style attribute }\end{array}$ & Attribute definition \\
\hline \multirow[t]{2}{*}{ Perception } & \multirow[t]{2}{*}{$\begin{array}{l}\text { How does the } \\
\text { student tend to } \\
\text { perceive the world? }\end{array}$} & Sensory & $\begin{array}{l}\text { a sensory student perceives the world mainly by observing it } \\
\text { and by gathering data through the senses; (s)he tends to be } \\
\text { concrete, practical, oriented towards facts, procedures, and } \\
\text { experimentation; (s)he is good in memorizing the above kinds } \\
\text { of information; (s)he tends to solve problems by exploiting } \\
\text { standard methods }\end{array}$ \\
\hline & & Intuitive & $\begin{array}{l}\text { an intuitive student perceives the world mainly through } \\
\text { intuition, i.e., indirect perception by way of the unconscious - } \\
\text { speculation, imagination, hunches; (s)he can be innovative, } \\
\text { good in grasping new concepts, creative, able of "inspired } \\
\text { guesswork" }\end{array}$ \\
\hline \multirow[t]{2}{*}{ Input } & \multirow{2}{*}{$\begin{array}{l}\text { Through which } \\
\text { sensory channel } \\
\text { does the student } \\
\text { prefer to receive } \\
\text { external } \\
\text { information? }\end{array}$} & Visual & $\begin{array}{l}\text { a visual student remembers best what (s)he perceives in a non } \\
\text { strictly verbal form (e.g., pictures, diagrams, flow charts, } \\
\text { symbols, videos) }\end{array}$ \\
\hline & & $\begin{array}{l}\text { Auditory/Verb } \\
\text { al }\end{array}$ & $\begin{array}{l}\text { an auditory/verbal student remembers much of what (s)he } \\
\text { hears and then says; (s)he likes auditory presentation (e.g., } \\
\text { lecturing) or visual representation of auditory information } \\
\text { (e.g., words, mathematical symbols, ...) }\end{array}$ \\
\hline \multirow[t]{2}{*}{$\begin{array}{l}\text { Process/ } \\
\text { Knowledge } \\
\text { Building }\end{array}$} & \multirow{2}{*}{$\begin{array}{l}\text { How do students } \\
\text { prefer to process } \\
\text { information and } \\
\text { convert it into } \\
\text { knowledge? }\end{array}$} & Active & $\begin{array}{l}\text { an active student learns best by doing something "physical” } \\
\text { (i.e., something in the external world) with the information, } \\
\text { e.g., experimentation }\end{array}$ \\
\hline & & Reflexive & $\begin{array}{l}\text { an active student learns best applying some forms of reflective } \\
\text { observations, examining information introspectively, focusing } \\
\text { on the internal world of ideas, drawing analogies, and } \\
\text { formulating personal views and interpretation of the } \\
\text { information }\end{array}$ \\
\hline \multirow[t]{2}{*}{$\begin{array}{l}\text { Process/ } \\
\text { Understanding }\end{array}$} & \multirow[t]{2}{*}{$\begin{array}{l}\text { How does the } \\
\text { student progress } \\
\text { towards } \\
\text { understanding? }\end{array}$} & Sequential & $\begin{array}{l}\text { a sequential student prefers to proceed in a logically ordered } \\
\text { progression, with each step following logically from the } \\
\text { previous one; (s)he understands a complex issue through } \\
\text { small, analytical, incremental steps; (s)he tends to follow } \\
\text { logical stepwise paths in finding solutions and, even if (s)he } \\
\text { does not fully understand the material can nevertheless do } \\
\text { something with it (e.g., solve relatively simple problems) }\end{array}$ \\
\hline & & Global & $\begin{array}{l}\text { a global student learns in "fits and starts", and must get "the } \\
\text { big picture” before individual pieces fall into place (but at this } \\
\text { point (s)he can put things together in novel ways) ; (s)he does } \\
\text { better by jumping directly to more complex and difficult } \\
\text { material than absorbing each detail of a subject }\end{array}$ \\
\hline
\end{tabular}


Table 2

Design properties/dimensions

\begin{tabular}{|c|c|c|c|}
\hline $\begin{array}{l}\text { Design } \\
\text { dimensions }\end{array}$ & Question about... & $\begin{array}{l}\text { Design } \\
\text { properties }\end{array}$ & Examples of design property “attributes” \\
\hline \multirow{4}{*}{$\begin{array}{l}\text { Concepts } \\
\text { and } \\
\text { Content }\end{array}$} & \multirow{4}{*}{$\begin{array}{l}\text { Which educational } \\
\text { material should the } \\
\text { application provide? }\end{array}$} & Concept types & $\begin{array}{l}\text { Fact, phenomenon, example, theory, principle, } \\
\text { demonstration, consequence, application, comment, }\end{array}$ \\
\hline & & Relationship type & $\begin{array}{l}\text { Precondition, assumption for, consequence of, example of, } \\
\text { application of, exemplification of, details for, }\end{array}$ \\
\hline & & Object structure & $\begin{array}{l}\text { - Rich structure (composite objects, with clearly identifiable } \\
\text { components) } \\
\text { - Poor structure (simple objects) }\end{array}$ \\
\hline & & Media types & $\begin{array}{l}\text { - Visual: image, video, animation, diagram, } \\
\text { - Sound } \\
\text { - Text }\end{array}$ \\
\hline Interaction & $\begin{array}{l}\text { Which interaction } \\
\text { style? }\end{array}$ & $\begin{array}{l}\text { Interaction Style } \\
\text { on active media }\end{array}$ & $\begin{array}{l}\text { - Active (full control) } \\
\text { - Couch potato (passive) }\end{array}$ \\
\hline Navigation & Which navigation style? & $\begin{array}{l}\text { Navigation } \\
\text { topology }\end{array}$ & $\begin{array}{l}\text { Possible “navigation patterns” to explore collections of } \\
\text { objects or interrelated objects [15], e.g.: } \\
\text { - Guided tour } \\
\text { - Index } \\
\text { - All-to-all } \\
\text { - Hierarchy }\end{array}$ \\
\hline Activity & $\begin{array}{l}\text { Which operations and } \\
\text { activities can the } \\
\text { learner be engaged } \\
\text { with? }\end{array}$ & $\begin{array}{l}\text { Operation/Activit } \\
\text { y Template }\end{array}$ & $\begin{array}{l}\text { - Mark topics of interest and collect them in a personal bag } \\
\text { - Answer questions posed by the system } \\
\text { - Fill in assessment questionnaires } \\
\text { - Participate to collaborative activities }\end{array}$ \\
\hline \multirow[t]{4}{*}{ Lay-out } & \multirow{4}{*}{$\begin{array}{l}\text { Which lay-out } \\
\text { properties for contents } \\
\text { and interaction } \\
\text { elements? (e.g., } \\
\text { navigation/ } \\
\text { operational buttons, } \\
\text { etc.)? }\end{array}$} & $\begin{array}{l}\text { Composition } \\
\text { style }\end{array}$ & many/few content elements in the same page \\
\hline & & Colors & many/few colors \\
\hline & & $\begin{array}{l}\text { Media } \\
\text { formatting }\end{array}$ & Big /small size, \\
\hline & & $\begin{array}{l}\text { Interaction } \\
\text { placeholders }\end{array}$ & $\begin{array}{l}\text { - Textual } \\
\text { - Iconic } \\
\end{array}$ \\
\hline
\end{tabular}

\section{Mapping Learning Styles to Design:}

\section{Patterns for Educational Hypermedia}

The modeling framework outlined in the previous section allows us to represent a pattern for educational hypermedia in an abstract way, in terms of a many-tomany relationship from learning attributes to design properties (see Fig. 1).

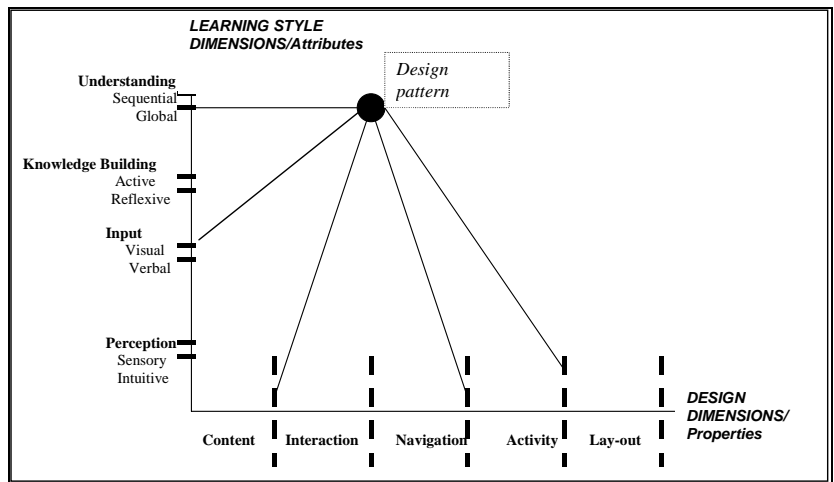

Figure 1. Conceptual Representation of Educational Hypermedia Patterns
Even though design patterns usually have a richer structure template $[17,18,19,20]$, we adopt a simplified format based on two components: <problem, solution>. The solution component is structured in various subcomponents discussing portions of a design solution along different design dimensions (content, navigation and interaction, activities, and lay-out). These are suggestions rather than prescriptions, and are intentionally incomplete: As for any design pattern, they offer guidance but require embellishment.

In the following example, we show the "Global Learner" pattern, which presents the design features that an educational hypermedia application may support to address the needs of a learner having a "global” learning preference.

As shown by the example, the design solutions expressed by the our patterns predicate about types of contents, organization structures, media types, navigation topologies, interaction modes, interface templates, and similar. Using a software engineering or a data base 
terminology, we can say that these are schema properties that concern the "general shape" of the application, i.e., its "design in the large", rather than local, fine grained features, which instead concern with the so called "design in the small". Accordingly, we can say that our educational hypermedia patterns provide guidelines for design in the large, leaving the designers enough freedom when designing in the small, when they apply the design guidelines in the particular context and subject domain.

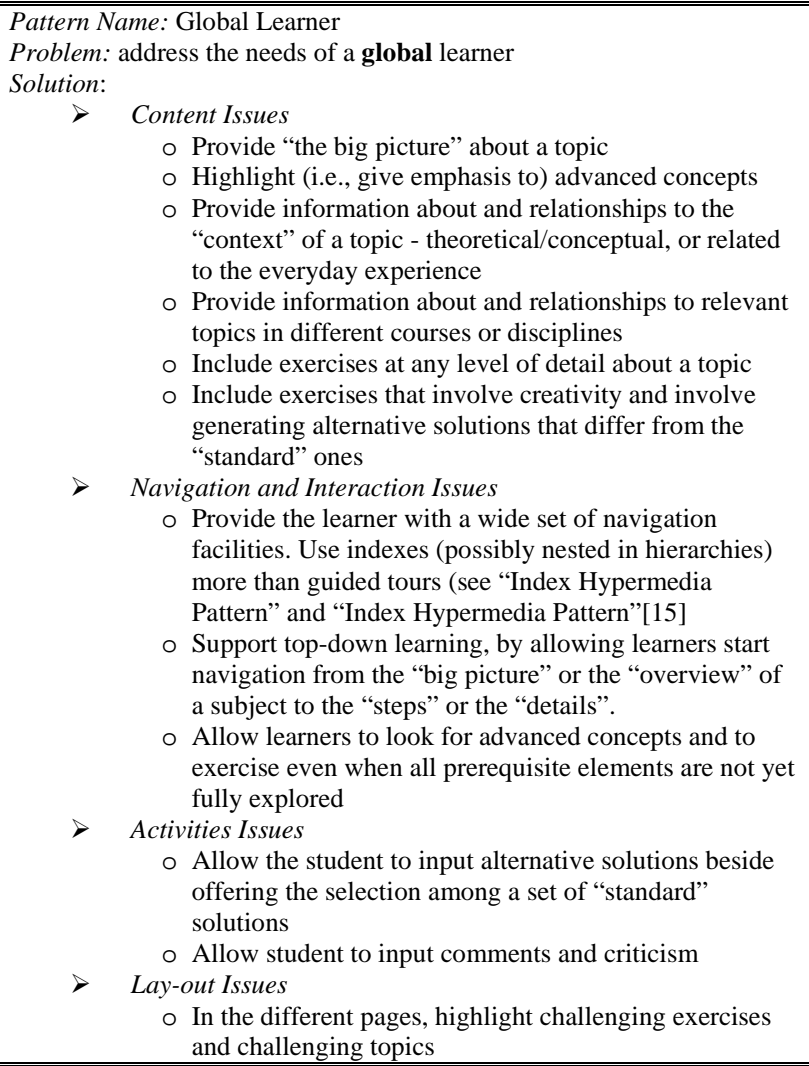

o Provide information about and relationships to relevant topics in different courses or disciplines

o Include exercises at any level of detail about a topic

o Include exercises that involve creativity and involve generating alternative solutions that differ from the "standard" ones

$>\quad$ Navigation and Interaction Issues

o Provide the learner with a wide set of navigation facilities. Use indexes (possibly nested in hierarchies) more than guided tours (see "Index Hypermedia Pattern” and "Index Hypermedia Pattern”[15]

o Support top-down learning, by allowing learners start navigation from the "big picture" or the "overview" of a subject to the "steps" or the "details".

o Allow learners to look for advanced concepts and to exercise even when all prerequisite elements are not yet fully explored

$>$ Activities Issues

o Allow the student to input alternative solutions beside offering the selection among a set of "standard" solutions

o Allow student to input comments and criticism

$>$ Lay-out Issues

o In the different pages, highlight challenging exercises and challenging topics

\section{Patterns for Adaptive and Adaptable Educational Hypermedia}

Design patterns like the one discussed in the previous section are conceived for "traditional" educational hypermedia, i.e., systems that have no adaptive or adaptable behavior. They offer guidelines for designing hypermedia features for a specific type of learner - the one having a specific learning style - in such as way that (s)he can find, at any time, the material, the interaction and navigation facilities, the proposed activities, structured and presented in a manner compatible with his or her learning preference.

Traditional educational hypermedia faces the problem of how to satisfy the needs of different categories of learners, who may have different learning preferences and therefore require different design solutions. Offering multiple co-existing design solutions into a single application, each one geared towards a different learning style, may cause usability problems. It creates a potentially complex educational space where the student may find difficult and time consuming to identify the material and interaction that is more appropriate to his or her learning preferences.

An approach to address this problem is to design multiple (but separate) customized views of the application, each one tuned to the needs of a specific learning style, and to exploit adaptive/adaptable hypermedia techniques to detect the user learning preferences and to offer the user a personalized view that is more appropriate to his or her learning style [21, 2, 22, 23]. Adaptable and adaptive hypermedia mainly differ in the way the learner model is detected by the system and the corresponding modifications of the hypermedia features are executed. In adaptable hypermedia, the learner has the control on the definition of the learner model: (S)he is responsible for providing the system with the attributes that, directly or indirectly, define his or her learner model. In adaptive hypermedia, the system infers aspects of a learner model by observing his or her interaction behavior.

As depicted in Fig. 2, in this approach each customized view (no matter if it is generated using adaptable or adaptive techniques) exploits design patterns for education hypermedia like the ones exemplified in the previous section.

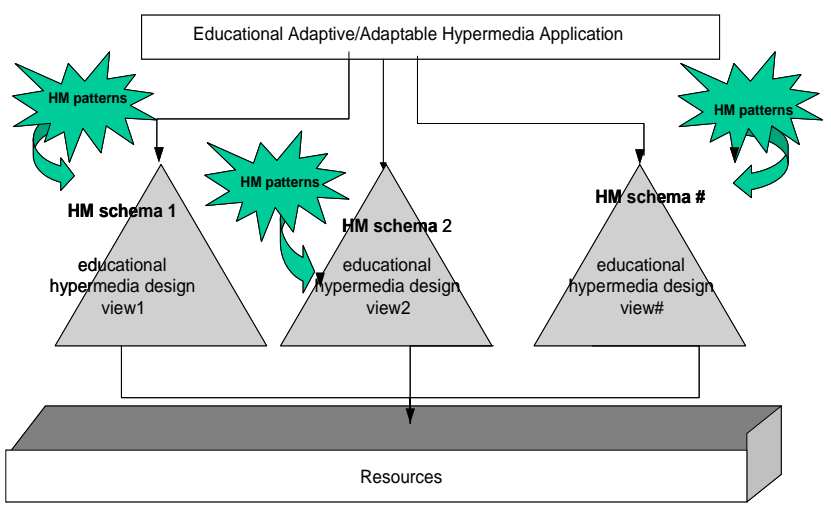

Figure 2. Customized Design Views of the Educational Hypermedia Application

The detection of the learning preferences that triggers the personalization of the design can take several forms, which may require adaptability or adaptivity, depending on the case.

Personalization can either result from different types of learner's interaction that are explicitly related to learning style assessment, or it can be build on the basis of the learning flow ${ }^{2}$. Examples of events that trigger personalization include:

\footnotetext{
${ }^{2}$ An example is an activity sequence, where the following activity may only be accessed after the previous one has been
} 
- A learner input of the learning preferences, or a learner switch to a different set of learning style.

- Completing a pre-test questionnaire that is related to the learner interests or attitudes, knowledge level, etc., from which the application derives the learning preferences or style.

- Completing a learning activity (e.g. a self assessment exercise).

- By "brute force", i.e., by re-evaluating the current personalization expressions for the learner to force him or her to exercise a different learning style (e.g., when desiring to achieve a certain teaching goal).

In the first two cases, the definition or update of the learner model is largely under the user responsibility (as it happens for adaptable hypermedia) and the user can (indirectly) control the design customization (i.e., the selection of the most appropriate design view).

In the last two cases, the definition or update of the learner model is largely under the system responsibility (as it happens for adaptive hypermedia) and it's the system which control the selection of the most appropriate design view.

In this perspective, we need to define design patterns that could provide a solution to the problem of how to construct both adaptive and adaptable educational hypermedia. These patterns can be regarded as high level pedagogical strategies to help the design of the in-thelarge customization behavior of this class of systems. The rest of this section will present three examples of adaptivity/adaptability patterns; each one can be used to design either an adaptive or an adaptable educational hypermedia depending on the detection mechanism adopted by the system.

The first pattern basically defines a general strategy - the need of selecting the proper customized schema on the basis of the currently detected learning styles. The second and third pattern suggest that in some cases different learning experiences should be provoked, by forcing a customization based on learner's preferences different from the current ones. The second pattern suggests this solution in cases when the learning performance detected by the system is considered unsatisfactory. The third pattern applies the Felder's principle of "finding a balance in instructional methods" in order to stimulate different learning styles.

\section{Adaptivity/Adaptability Pattern - Customization in the large-}

$>$ Problem: once the system detects a (change of) some learning preferences in the learner model, how can the application be customized?

$>$ Solution: apply the "design schema" which is more appropriate for the current learning preferences; the schema

completed, assuming, that is, that the activity was not the first one in the sequence [8]. should adhere to the HM patterns corresponding to that learning style

\section{Adaptivity/Adaptability Pattern - Learning Style Brute-force Exposure}

> Problem: the system detects some failures in the learning process. Which "compensating actions" can be taken by the system?

$>$ Solution:

enforce the adoption of a different learning style, by changing a "learning style" preference in the learner model, and consequently, by applying a different hypermedia version of the hypermedia material. Notify the learner of this change

\section{Adaptivity/Adaptability Pattern - Balancing Learning Styles}

$>$ Problem: the system wants to stimulate the learner's mental flexibility (to help students builds their skill both in their preferred and less preferred learning modes)

$>$ Solution:

After a number of sessions customized to the user learning style, provide a different experience, enforce (or propose) the adoption of a different learning style (or more than one) and consequently, the application of a different hypermedia schema based on a different set of hypermedia design patterns. Notify the learner of this change

To support the above types of customisation and to conform to the aforementioned design strategies, adaptive/adaptable educational hypermedia should be designed with a different philosophy, which may lead to a new generation of adaptable or adaptive educational hypermedia. Beside the conventional customization in the small (adaptation of local navigation and content properties, individual instances, or detailed lay out features), these systems should explicitly support customisation in the large, where different types of content, different navigation paradigms, and perhaps different operations and lay-out templates are offered to learners depending on their learning preferences,

To achieve the above goal, adaptive and adaptable hypermedia should improve the representation of the learner model, support the separation of concerns among the different features of the system, and provide a more powerful run time environment to implement schema views. In particular, the Learner Model should be enriched. Enrichment should not necessarily concern the "conventional" overlay sub-model $[24,25]$, which is the domain specific part of the Learner Model and defines the status of the learner's knowledge of the specific concepts covered by the learning material. This part of the learner model could be exploited as usual to support customization in the small. Improvements are needed in the second part of the Learner Model (which, according to [24], constitutes the Stereotyped Learner sub-model). This sub-model should define both the elements that are used to represent the usually predefined learner knowledge profile (concerning the knowledge level of the particular domain, e.g., novice, intermediate, expert) and the 
learner's preferences, attitudes, traits, etc. - which capture the learning style needed for customization in the large as proposed by our design patterns.

\section{Conclusions}

The core idea of our approach is the attempt to translate to the field of hypermedia based e-learning the concepts expressed by the following statement in traditional instructional design:

"Students preferably take in and process information in different ways: by seeing and hearing; reflecting and acting; reasoning logically and intuitively; memorizing and visualizing and drawing analogies and building conceptual models; steadily and in fits and starts. ... How much a given student learns is governed in part by that student native ability and prior preparation but also by the compatibility of his or her learning style and the instructor teaching style... If professors teach exclusively in a manner that favors their less preferred learning style modes, the students' discomfort may be great enough to interfere with their learning. On the other hand, if professors teach exclusively in their students preferred modes, the students may not develop the mental dexterity they need to reach their potential for achievement in school and as professionals" [4, 26].

In order to achieve similar goals in e-learning, we need to build systems that are designing with a focus on the learners' needs, and can eventually adapt the general properties of content, navigation, and lay out features according to the user learning preferences.

The goal of this paper is to initiate the dialogue for designing adaptive/adaptable educational hypermedia systems following techniques of the hypermedia engineering. We introduced the notion of design patterns which seems to be the key in achieving the economy of scale for building affordable software systems, supporting reuse in the form of analysis, design, or architectural components (which is even more important than simple code reuse).

The main goal of the paper is to show that learning preferences and hypermedia design are related. and to propose design patterns for e-learning that provide solutions to the problem of how to best support learning preferences via educational hypermedia. Moreover, by presenting design patterns as strategies for adaptive/adaptable educational hypermedia, we specify a new set of requirements for a new generation of such systems.

We are optimistic that design patterns are the proper conceptual tools. Still, it is evident that further investigation and a lot of R\&D effort should be performed. The patterns presented here need to be tested and elaborated through empirical studies and system implementations. Further work needs to be undertaken to exploit the progress of learning technologies standards, which can aid in the description of the learning resources with meta-data, in the creation of an ontology for a learner profile, and in the design and structuring of the learning resources content according to specific rules.

Within two European partnership projects, the E-LEN project [www.tisip.no/ELEN] and the ADAPT project [wwwis.win.tue.nl/ acristea/HTML/Minerva], special interest groups have been formed to share and develop design patterns regarding e-learning both for traditional hypermedia and for adaptive/ adaptable hypermedia, laying the foundations for a pattern language for such systems.

\section{Acknowledgement}

This work was partially supported by the "ELEN: A Network of elearning centers" project and the ADAPT project which are partly sponsored by the European Commission under Socrates Minerva program (ref nums: 101421-CP-1-2002-1-CY-MINERVA-M and 101144 CP -1-2002-1- NL - MINERVA - M).

\section{References}

[1] G. Pask. Styles and strategies of learning. British Journal of Educational Psychology, 46, pp.128-48.

[2] N. Ford, and S. Chen. Individual differences, hypermedia navigation and learning : an empirical study, Journal of Educational Multimedia and Hypermedia, 2000, 9 (4), pp. 281-311

[3] M. Lumsdaine and E. Lumsdaine. "Thinking Preferences of Engineering Students: Implications for Curriculum Restructuring." Journal Engineering Education, 84 (2), 193-204 (1995).

[4] R.M. Felder and L.K. Silverman. Learning Styles and Teaching Styles in Engineering Education. Engineering Education, 78 (7), 674-681 (1988).

[5] R. Dunn and K. Dunn. Teaching Students through their individual learning styles: A practical Approach (Reston Publishing Division of Prentice-Hall Publisher, Reston, Va, 1978).

[6] C.S. Claxton, and P.H. Murrell. Learning Styles: Implications for Improving Educational Practice. ASHEERIC Higher Education Report No. 4, ASHE, College Station, 1987

[7] R.M. Felder, G.N. Felder, and E.J. Dietz, The Effects of Personality Type on Engineering Student Performance and Attitudes. Journal Engineering Education, 91 (1), 317 (2002).

[8] P. Brusilovsky. Adaptive hypermedia. User Modeling and User Adapted Interaction, Ten Year Anniversary Issue (A. Kobsa, ed.) 11 (1/2), 87-110

[9] C. Alexander, S. Ishikawa, M. Silverstein, M. Jacobson, I. Fiksdahl-King, \& S. Angel. A Pattern Language (Oxford University Press, New York, 1997).

[10] R.J. Riding and I. Cheema. Cognitive style. An overview and integration, Educational Psychology - 
International Journal of experiential educational psychology VII, No 3-4, pp.193-125 (1991)

[11] D. Kolb. Experiential Learning: Experience as the Source of Learning and Developmen (Prentice-Hall, Englewood Cliffs, NJ, 1984).

[12] J.A. Clarke. Cognitive style and computer assisted learning problems and a possible solution, Association for Learning Technology Journal (ALT-J) Vol.1, (1) pp. 4759.

[13] F. Garzotto, L. Mainetti, P. Paolini. "Hypermedia Design, Analysis, and Evaluation Issues". In Communications of the ACM, 38 (8), Aug. 1995

[14] D. Scwhabe \& G. Rossi, The Object-Oriented Hypermedia Design Model (OOHDM), Communications of the ACM, Vol. 35, no. 8, August 1995.

[15] T. Isakowitz; E. Stohr; P. Balasubramaniam, RMM, A methodology for structured hypermedia design, Communications of the ACM, Vol. 35, no. 8, pp 34-48

[16] S. Ceri, P. Fraternali, A. Bongio. Web Modeling Language (WebML): a modeling language for designing Web sites, Proceedings of the 9th World Wide Web Conference (WWW9), Amsterdam, 2000

[17] F. Garzotto, P Paolini, D. Bolchini, S. Valenti, Modeling-by-patterns of web applications. In Advances in Conceptual Modeling, P. Chen. D. Embley, J, Kouloumdjian, S. Little (eds.), Lecture Notes in Computer Science 1727, (Springer 1999).

[18] E. Gamma, R. Helm, R. Johnson and J. Vlissides, Design Patterns. Elements of Reusable Object-Oriented Software (Addison-Wesley, 1996)

[19] G. Rossi, D. Schwabe and F. Lyardet, "Improving Web Information Systems with Design Patterns". In Proceedings of the 8th International World Wide Web Conference, Toronto (CA), May 1999, Elsevier Science, 1999.

[20] M. Nanard, J. Nanard and P. Kahn. "Pushing Reuse in Hypermedia Design: Golden Rules, Design Patterns and Constructive Templates". In Proceedings of the ACM International Conference on Hypertext '98, ACM Press, 1998, pp. 11-20.

[21] H.L. Daniels, Interaction of cognitive style and learner control of presentation mode in a hypermedia environment, PhD Dissertation, Blacksburg, Virginia

[22] M. Kwok, and C. Jones. (1985) Catering for different learning styles, Association for learning Technology (ALT-J) 3, 1, pp.5-11

[23] K. Papanikolaou, M. Grigoriadou, H. Kornilakis. Instructional and Interface Design in an Adaptive Educational Hypermedia System, Human Computers Interaction 2001, Panhellenic Conference with International Participation, Patra

[24] P. Brusilovsky, Methods and techniques of adaptive hypermedia. User Modeling and User Adapted Interaction, Vol. 6, pp 87-129, 1996.

[25] P. De Bra, P. Brusilovsky, and Houben, G.-J. Adaptive Hypermedia: From Systems to Framework. ACM Computing Surveys, 31 (4es) December 1999
[26] R.M. Felder, "Reaching the Second Tier: Learning and Teaching Styles in College Science Education," Journal. Coll. Sci. Teaching, 23 (5), 286--290 (1993).

\section{About the authors}

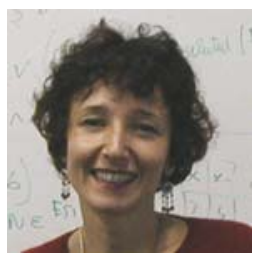

Professor Dr. Franca Garzotto has a Degree in Mathematics from University of Padua (Italy) and a Ph.D. in Computer Science from Politecnico di Milano, where she is currently Associate Professor of Computer Engineering at the Dept. of Electronics and Information. Since 1988, she has been active in hypertext, multimedia, web applications, focusing on design, usability, adaptive human computer interaction and participating in over 15 European and national research projects on these topics. She was program committee member of many editions of the ACM Hypertext conference, the ACM Multimedia Conference, ICHIM, and "Museums and the Web". She served as co-organizer of several international workshops on hypermedia related topics and program chair of ICHIM'01 (Milan 2001 - the largest worldwide conference on ICT applications to cultural heritage). She was European chair of ACM SIG-WEB (ACM Special Interest Group on Hypermedia \& Web) from 1997 to 1999.

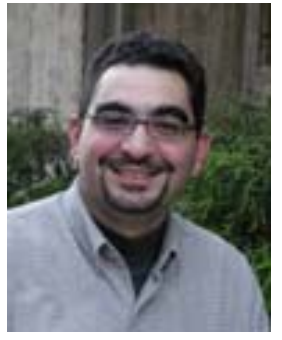

Dr. Symeon Retalis is Assistant Professor at the Department of Technology Education \& Digital Systems, University of Piraeus.

He holds a diploma of Electrical and Computer Engineer as well as a $\mathrm{PhD}$ from the National Technical University of Athens, Greece and an MSc on Knowledge Management from the AI Department of the University of Athens. His research interests lie on the development of web-based learning systems, design of adaptive hypermedia systems, web engineering, and human computer interaction. He has participated in various European R \& D projects. He serves in the editorial board of international journals such as Computers in Human Behavior, IEEE Journal of Educational Technology and Society, ACM Computing Reviews. He participates to the ACM Web Engineering special interest group, to the CEN/ISSS learning technologies workshop. His publication list contains more than 70 items. 


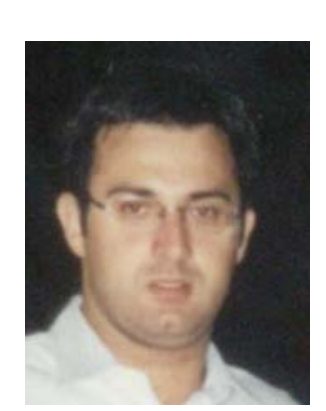

Dr. Konstantinos Siassiakos holds a diploma (1995) of Electrical and Computer Engineer from the Department of Electrical and Computer Engineering studies, University of Patras, Greece, and a Ph.D. (2001) diploma from the Department of Electrical and Computer Engineering, National Technical University of Athens, Greece. He has worked as an I.T consultant at Ministry of Development (General Secretariat of Industry) on the Operational Programme

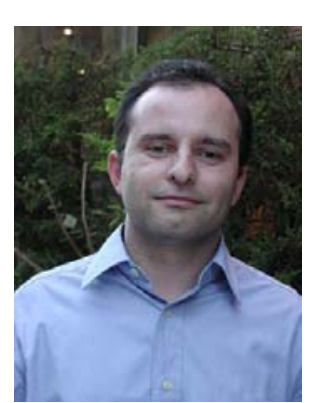

A. Papasalouros is a doctoral candidate at the School of Electrical and Computer Engineering of the National Technical University of Athens. He holds a B.Sc. in Physics (1992) from the University of Athens and a B.Sc. in Electrical and Computer Engineering (2000) from the National Technical University of Athens. He specializes in object-oriented software development methodologies, web engineering, learning management systems and adaptive hypermedia systems. He has participated in a number of European R\&D projects such as TELL, ELEN, MENU, UNIVERSAL, etc. His has published more than 20 papers in journals and conference proceedings.
«Competitiveness» and as a research at the Department of Technology Education \& Digital Systems, University of Piraeus. His research interests lie on the development of web-based learning systems, educational technologies, human computer interaction, quality assurance, business process reengineering, and e-government technologies. He has participated in various European R \& D projects such as TELL and SCOUT. His publication list contains more than 14 items. 